\title{
Green Electricity from Rice Husk: A Model for Bangladesh
}

\author{
A.K.M. Sadrul Islam and Md. Ahiduzzaman \\ Additional information is available at the end of the chapter \\ http://dx.doi.org/10.5772/55224
}

\section{Introduction}

Bangladesh has reportedly over one hundred thousand Rice Mills - large, medium and small. They process paddy, using mostly the parboiling practice. The rice mills use the thermal energy of steam generated in boilers, which are fired by rice husk - a byproduct of paddy processing in the rice mills and which is globally well-known as very convenient source of dry biomass energy of reasonable heat value. In global context, annual rice husk production is 137 million tonnes whereas, in Bangladesh, about 9.0 million tonnes of rice husk is produced reported in 2011 [1]. In Bangladesh context, out of 37.08 million tonnes of total biomass produced from agro-residues, rice husk contributes about $26 \%$ by mass [2]. At present about $67-70 \%$ of rice husk is consumed for steam producing in rice mills [3,4]. With a few exceptions, presently most of the 'boilers', used in these rice mills of Bangladesh are very inefficient. This results in a huge wastage of rice husk, which is an important source of biomass. Preliminary estimates are indicative that at least $50 \%$ of the rice husk produced could be saved and made surplus for its better use as input for small power generation [5]. Energy demand for rice processing is increasing every year due to the increased production of rice for ensuring food security of the population. More energy efficient rice parboiling boilers is to be suggested to replace the existing inefficient rice parboiling systems. So that the surplus amount of rice husks could be available for other sectors. If this husk is to be briquetted, then it will be an alternative fuel for replacing wood-fuel. Rice husk based co-generation system could be an alternative for large rice mills, or even for a cluster of small to medium rice mills. If the electricity were generated from rice husk then net carbon dioxide emissions could be reduced [6]. As a matter of basic dissemination strategy, applicable to most of the developing countries, initially the entrepreneurs/investors feel shy to invest in a relatively new area technology, as they lack the confidence on the technical functioning and financial/economic viability of ventures in such an area. Before launching a husk based power generation technology, it is important to know the 
production and distribution of available rice husk resource at different location. There are some different options to enhance the availability of rice husk such as increasing the un-parboiled process, improvement of thermal and combustion efficiency of existing husk fired boiler for parboiled process of paddy. Another important issue is the sustainable supply of rice husk in future for husk based power generation plant. Therefore, rice husk production and supply system is analyzed for electricity generation from husk in Bangladesh.

\section{Methodology}

There are main two sector of rice process viz. household level process and processed in rice mill. Husk obtained from household level process cannot be collected due to its wide spread localized. Therefore, husk from household level process is not considered as supply source of husk for electricity generation. Paddy processed in rice mill is considered the source of husk supply. There are several rice processing zones in the country. To conduct the investigation four major rice processing zones were selected to estimate potential husk available for electricity generation. The selected rice mill clusters are located at Dinajpur, Naogaon, Bogra, and Ishawrdi (Pabna). A survey questionnaire was used to collect the information on monthly quantity of paddy processed, amount of husk produced, amount of husk consumed for rice processing purposes and the surplus amount of rice husk (Survey questionnaire is shown in Appendix). Two hundred number of rice mills were surveyed in this study.

Another study is conducted to estimate the total electricity generation from rice husk in Bangladesh. LEAP (Long-range Energy Alternative Planning System) tool is used to make three different scenarios for consumption of energy. The basic parameter for estimating scenarios data are shown in Table 1.

\begin{tabular}{lll}
\hline Activity level & Reference scenario & Scenario-1 \\
\hline Paddy processed in mill & $70 \%$ & $90 \%$ \\
\hline Parboiled processed paddy & $90 \%$ & $90 \%$ \\
\hline Unparboiled processed paddy & $10 \%$ & $10 \%$ \\
\hline Traditional parboiling & $100 \%$ & $5 \%$ \\
\hline Improved parboiling & 0 & $95 \%$ \\
\hline
\end{tabular}

Table 1. Assumption of activity levels at different scenario

\section{Results and discussion}

\subsection{Available husk at rice mills}

Annual paddy processing capacity and surplus amount of husk from the four selected rice processing zones are analyzed. The annual paddy processing capacities were estimated to be 
936923, 394976, 1366980 and 925048 tonne per year for Pulhat (Dinajpur), Bogra, Naogaon and Ishawrdi cluster, respectively. Total paddy processed in these clusters was 3.62 million tonne. Amount of surplus husk for selected rice processing zones were estimated to be 82904,586925 , 192551 and 121209 tonne per year for Pulhat, Bogra, Naogaon and Ishawrdi cluster, respectively. Total surplus of husk were 455356 tonne per year in the selected four clusters.

\subsection{Electricity generation capacity based on rice husk energy at the study areas}

Electricity generation from rice husk depends on the availability of raw material and the technology for conversion rice husk to energy. For a steam turbine power plant consumption of rice husk is $1.3 \mathrm{~kg}$ per $\mathrm{kWh}$ electricity as reported by Singh [7]. On the other hand for a gasification power plant consumption of rice husk is $1.86 \mathrm{~kg}$ per $\mathrm{kWh}$ electricity generation [8]. Based on this assumption the capacity of electricity power generation was estimated for the study areas (Table 2). The potential power capacities is estimated to be $41450 \mathrm{~kW}$ in four selected zones considering the steam turbine technology, whereas the corresponding power capacities is estimated to be $29050 \mathrm{~kW}$ considering gasification technology.

\begin{tabular}{|c|c|c|c|}
\hline \multirow{4}{*}{$\begin{array}{l}\text { Rice processing } \\
\text { zone }\end{array}$} & \multirow{4}{*}{$\begin{array}{l}\text { Available husk from } \\
\text { rice mill, ' } 000 \text { ' tonne/yr }\end{array}$} & \multicolumn{2}{|c|}{ Potential of electricity generation } \\
\hline & & Steam turbine plant & Gasification plant \\
\hline & & kW & kW \\
\hline & & @1.3 kg husk/kWh ${ }^{*}$ & @ $1.86 \mathrm{~kg}$ husk $/ \mathrm{kWh}_{\mathrm{e}}{ }^{* *}$ \\
\hline Dinajpur & 82.90 & 7250 & 5150 \\
\hline Ishawrdi & 121.21 & 10750 & 7500 \\
\hline Bogra & 58.69 & 5200 & 3600 \\
\hline Naogaon & 192.55 & 18250 & 12800 \\
\hline Total & 455.35 & 41450 & 29050 \\
\hline
\end{tabular}

Table 2. Summary of electricity production from rice husk

Husk supply from rice mills is not uniform in quantity throughout the year. Sometimes the husk supply is surplus so that the husk is leftover after consumption and sometimes the husk supply is deficit than needed. Therefore, further analysis is done to see the surplus and deficit pattern of husk supply throughout the year. In this study it is estimated that the husk supply is surplus for 8 months and the quantity of surplus amount is 19428 tonne for Dinajpur. This surplus amount of husk is to be stored for the use to overcome the deficit of rice husk for rest of four months of the year. The deficit amount is 17956 tonne, therefore surplus amount of husk is sufficient to overcome the deficit amount for $7250 \mathrm{~kW}$ steam turbine power plant at Dinajpurt area (Fig. 1). Similarly 18540 tonne of surplus husk is sufficient to make up 18399 tonne shortage of husk for gasification power plant at Dinajpur (Fig. 2). 
At Ishawrdi area, the husk supply is surplus for 9 months and the quantity of surplus amount is 16271 tonne. This surplus amount of husk is to be stored for the use to overcome the deficit of rice husk for rest of three months of the year. The deficit amount is 15806 tonne, therefore surplus amount of husk is sufficient to overcome the deficit amount for $10750 \mathrm{~kW}$ steam turbine power plant (Fig.3). Similarly 16432 tonne of surplus husk is sufficient to make up 15752 tonne shortage of husk for $7500 \mathrm{~kW}$ gasification power plant (Fig. 4).

At Bogra area, the husk supply is surplus for 9 months and the quantity of surplus amount is 2759 tonne. The deficit amount is 2474 tonne, therefore surplus amount of husk is sufficient to overcome the deficit amount for $5200 \mathrm{~kW}$ steam turbine power plant (Fig. 5). Similarly 3174 tonne of surplus husk is sufficient to make up 2335 tonne shortage of husk for $3600 \mathrm{~kW}$ gasification power plant (Fig. 6).

At Naogaon area, the husk supply is surplus for 9 months and the quantity of surplus amount is 23235 tonne. Whereas the deficit amount is 21299 tonne, therefore surplus amount of husk is sufficient to overcome the deficit amount for $18250 \mathrm{~kW}$ steam turbine power plant (Fig. 7). Similarly 22697 tonne of surplus husk is sufficient to make up 21477 tonne shortage of husk for $12800 \mathrm{~kW}$ gasification power plant (Fig. 8).

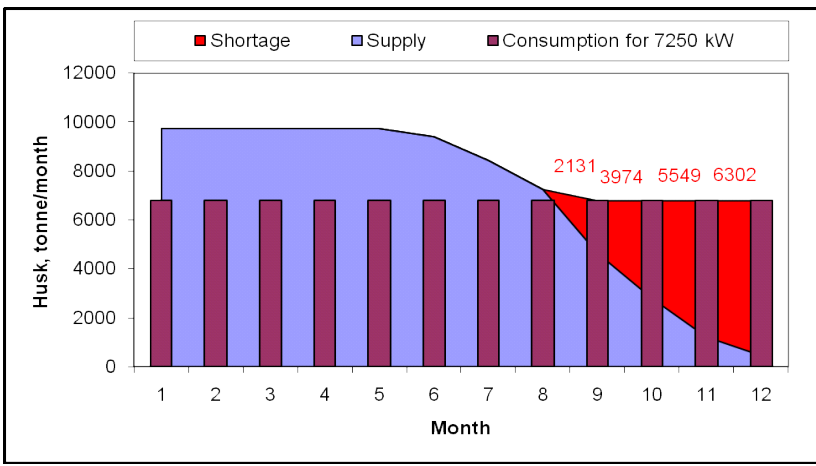

Figure 1. Potential production capacity of electricity at Pulhat for steam turbine plant 


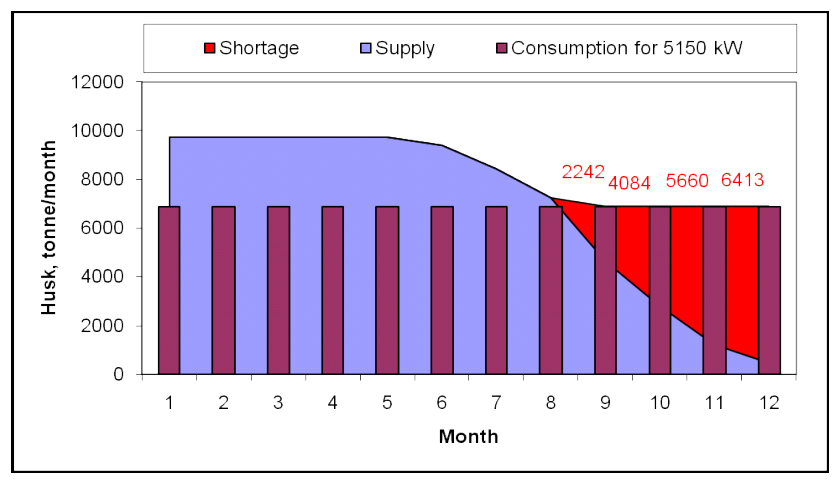

Figure 2. Potential production capacity of electricity at Pulhat for gasification plant

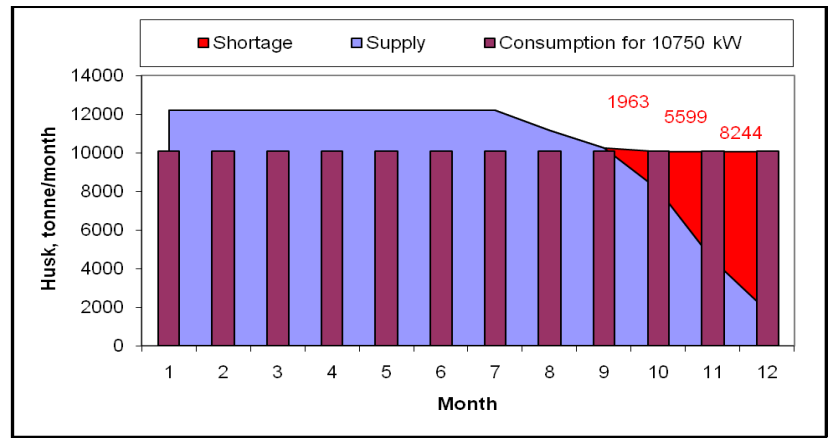

Figure 3. Potential production capacity of electricity at Ishawrdi for steam turbine plant

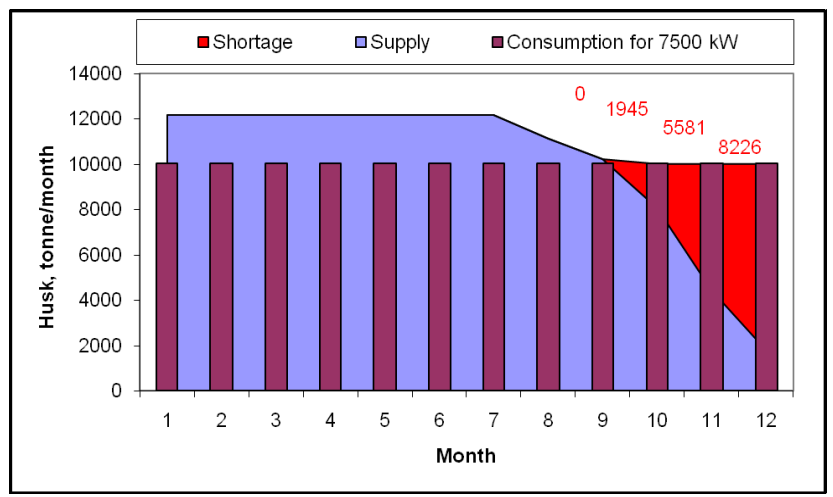

Figure 4. Potential production capacity of electricity at Ishawrdi for gasification plant 


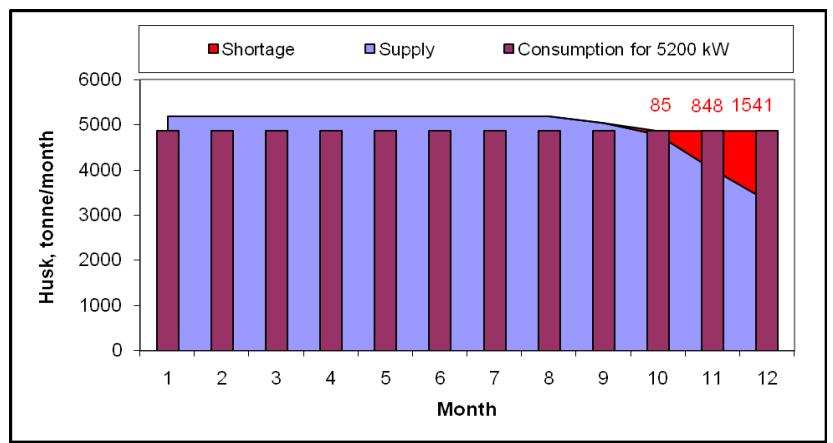

Figure 5. Potential production capacity of electricity at Bogra for steam turbine plant

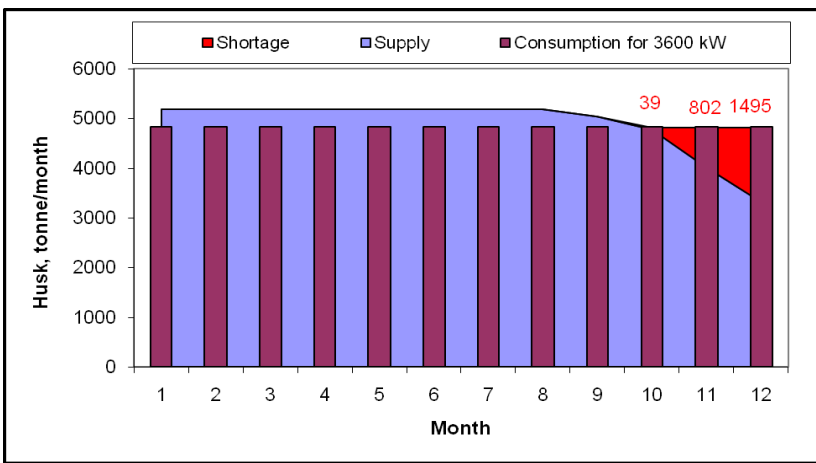

Figure 6. Potential production capacity of electricity at Bogra for gasification plant

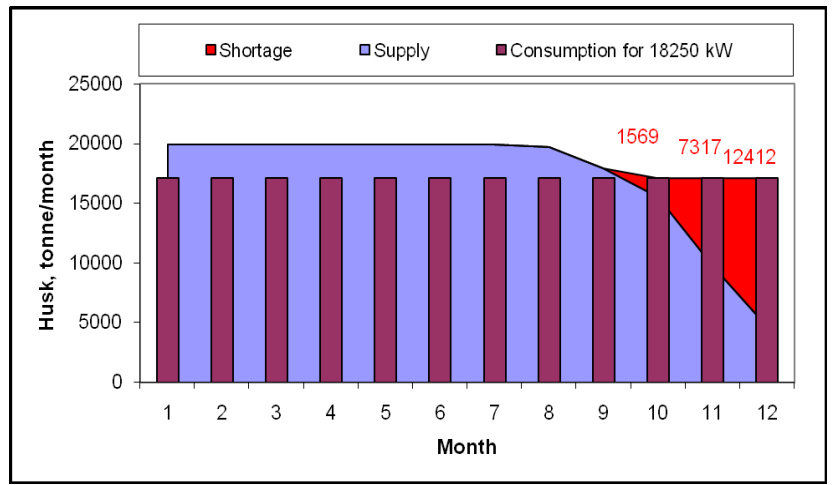

Figure 7. Potential production capacity of electricity at Naogaon for steam turbine plant 


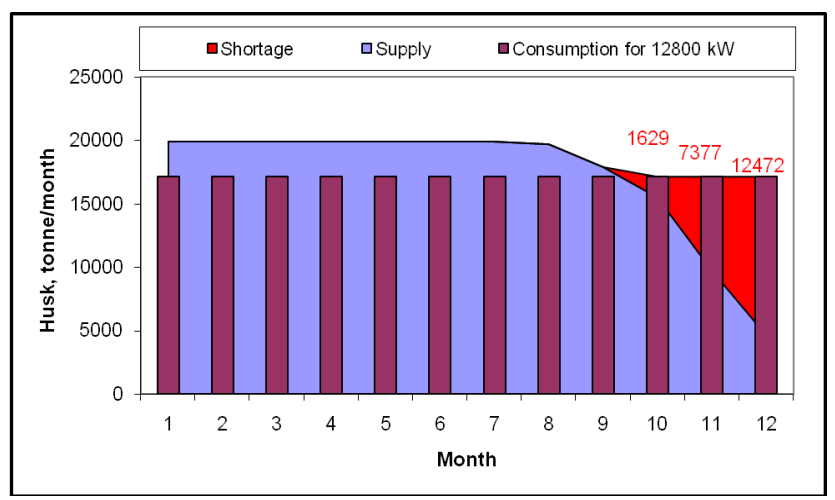

Figure 8. Potential production capacity of electricity at Naogaon for gasification plant

\subsection{Projection of future rice production in Bangladesh}

The production of rice is projected using the growth of $2.35 \%$. The growth is calculated from the average growth of rice production data from 1971 to 2009. The projected rice production is increased to 71 million tonne in 2030 (Fig 9).

\subsection{Rice processing in Bangladesh}

All produced paddy is not processed for preparation of food grain. About $5 \%$ of total paddy is used as seed for using next growing season. Among the rest of paddy about $70 \%$ is processed in local rice mill. The rest $25 \%$ of paddy is processed in rural household level. Rice husk is produced as by product in rice mill at the rate of $20 \%$ of mass fraction of paddy. The rice husk is primarily consumed for steam producing in parboiling process and drying process of paddy. The rest amount of husk could be an important source of husk based electricity generation plant.

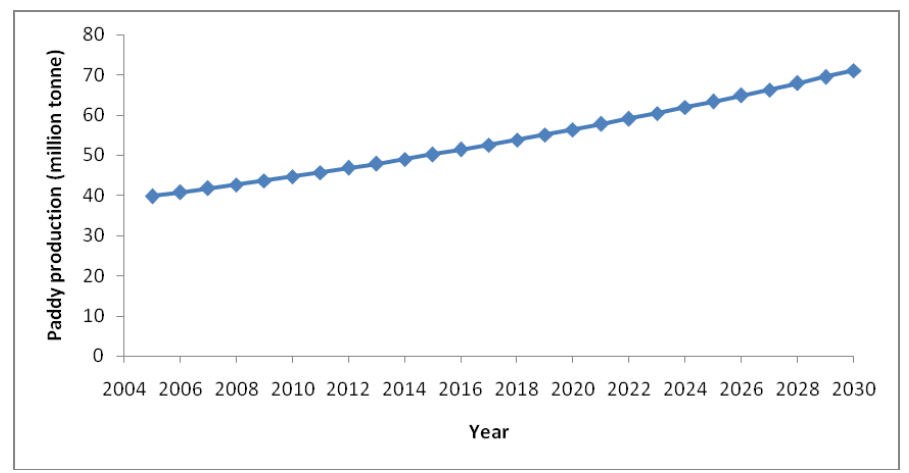

Figure 9. Raw rice production scenarion in Bangladesh 


\subsection{Husk produced in rice mill}

Amount of husk produced in rice mill depends on the amount of paddy processed in mill. Husk produced in rice mill could be increased by increasing the amount of processed paddy in mill. Share of paddy processed in mill is considered $90 \%$ of total paddy at the end of 2030 for scenario-1. As a result the husk production is increased from 9.96 million tonne (reference scenario) to 13.16 million tonne (Fig 10).

\subsection{Husk consumed in rice mill}

Husk is consumed primary for steam producing in rice parboiling process. More amount of parboiled paddy consumes more rice husk. At present about $90 \%$ of paddy is parboiled process. Therefore major amount of husk is consumed for parboiling of paddy. About $120 \mathrm{~kg}$ of husk is consumed for each tonne of paddy parboiled. The husk consumption for parboiling could be reduced from $120 \mathrm{~kg}$ to $49 \mathrm{~kg}$ for each tonne of paddy parboiled by replacing the traditional boiler with improved boiler. At present all boilers used are traditional type. In scenario-1, it is assumed that $95 \%$ of traditional boiler is to be replaced by improved boiler to reduce the husk consumption for parboiled process. The other way to reduce the rice husk consumption is reduction of parboiled coverage as well as enhancement of unparboiled process. The results of husk consumption for two different scenarios are shown in Fig 11. The husk consumption is reduction to 4.56 million tonne (Scenario-1) from 6.47 million tonne (reference).

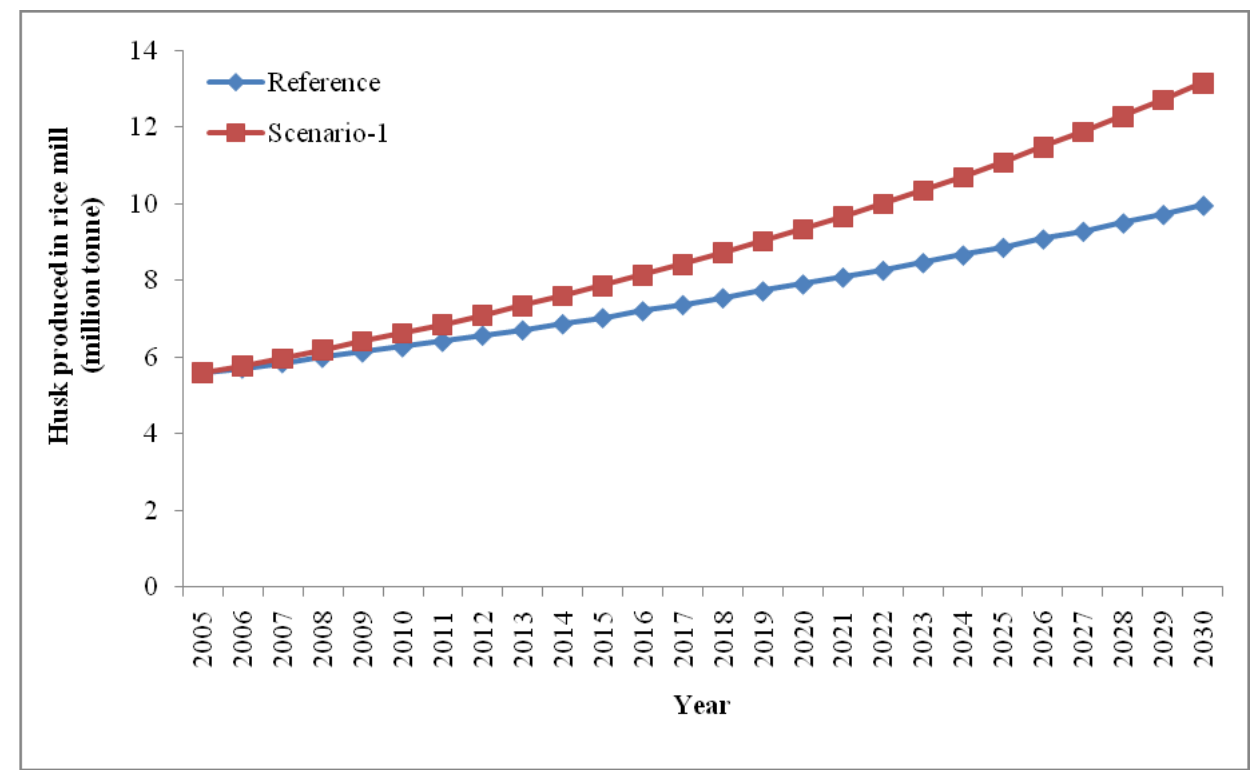

Figure 10. Rice husk production scenario in rice mill 


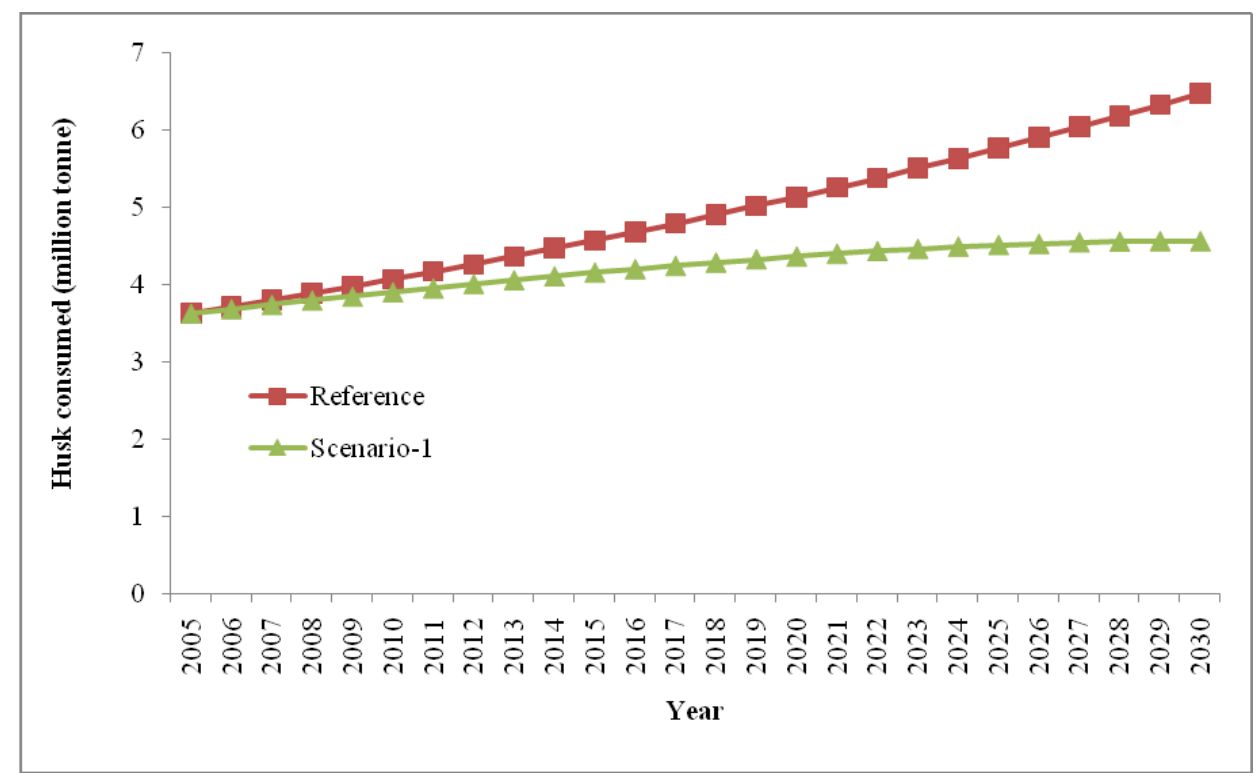

Figure 11. Rice husk consumption in rice mill at reference case ad scenario-1

\subsection{Husk surplus after consumed in rice mill}

The surplus amount of husk is calculated deducting the consumed amount of husk from total potential of husk ( $20 \%$ of paddy mass). The surplus amount of husk is increased to 8.60 million tonne (Scenario-1) from 3.49 million tonne (Reference) (Fig 12). The results show that there is huge potential to save rice husk by changing the technology for parboiling. 


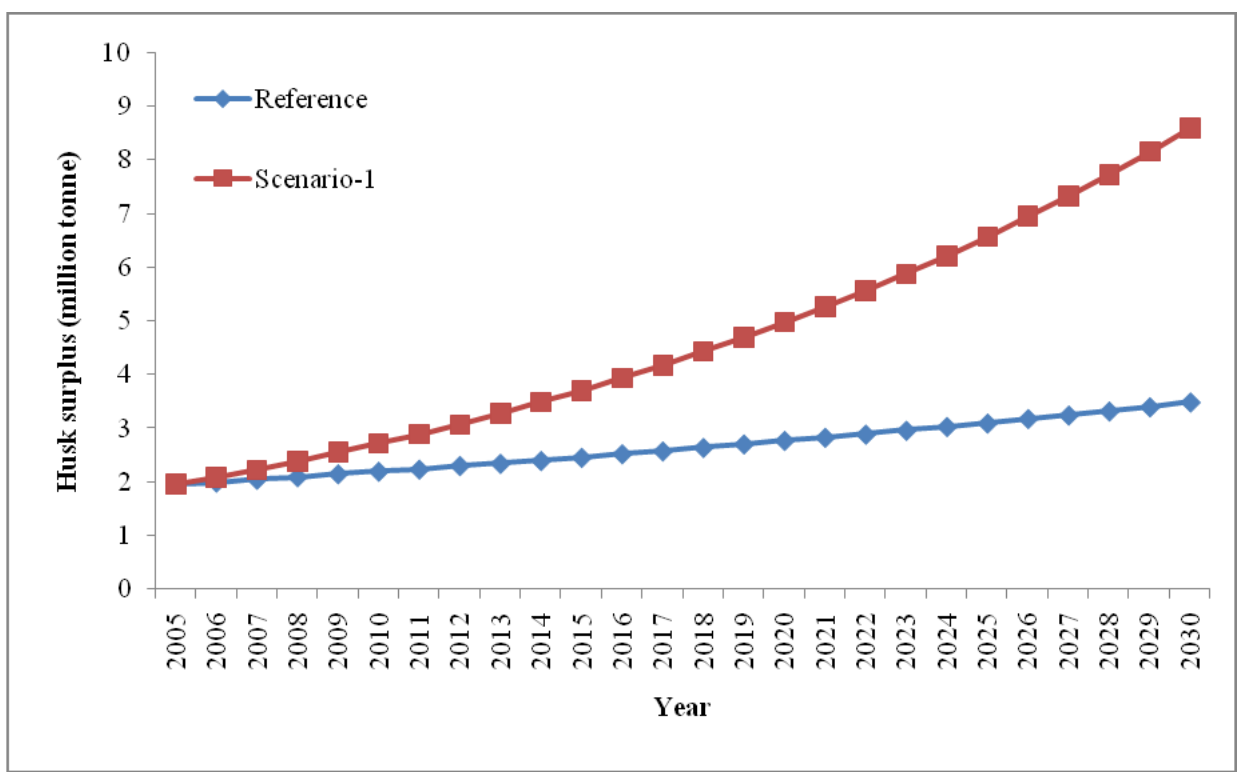

Figure 12. Rice husk surplus from reference case and scenarios-1

\subsection{Potential of electricity generation from rice husk}

Rice husk biomass easily can be used for electricity generation. Amount of electricity generated from rice husk depends on the amount of raw material and type of technology used for energy conversion. There are several technologies for electricity generation from biomass. In the present study steam turbine and gasification technology are considered for estimating the potential of electricity generated from surplus amount of husk from different scenarios. For a steam turbine power plant consumption of rice husk is $1.3 \mathrm{~kg}$ per $\mathrm{kWh}$ electricity as reported by Singh [7]. On the other hand for a gasification power plant consumption of rice husk is 1.86 $\mathrm{kg}$ per $\mathrm{kWh}$ electricity generation [8]. Based on this assumption the potential electricity generated from husk is presented in Fig 13 and Fig 14.

Potential electricity generated is estimated to be 1689 GWh (Reference), 2092 GWh (Scenario-1) in 2010 and these values will be increased to 2683 GWh (Reference) and 6612 GWh (Scenario-1) in 2030 for steam turbine technology use (Fig 13).

Potential electricity generated is estimated to be 1180 GWh (Reference) and 1462 GWh (Scenario-1) in 2010 and these values will be increased to 1875 GWh (Reference), 4621 GWh (Scenario-1) in 2030 for gasification technology use (Fig 14). Corresponding power capacities of husk based generation plant are shown in Fig 15 and Fig 16.

Electricity consumption for rice processing in Bangladesh is shown in Fig 17. Amount electricity consumed is estimated to be 812 GWh (Reference) and 891 GWh (Scenario-1) in 2010 and these values will be increased to 1292 GWh (Reference) and 2030 GWh (Scenario-1) in 2030. 
The results show that amount of electricity generated from rice husk is sufficient to meet the electricity needed for rice processing purposes. Moreover, surplus amount of electricity could be served to national grid.

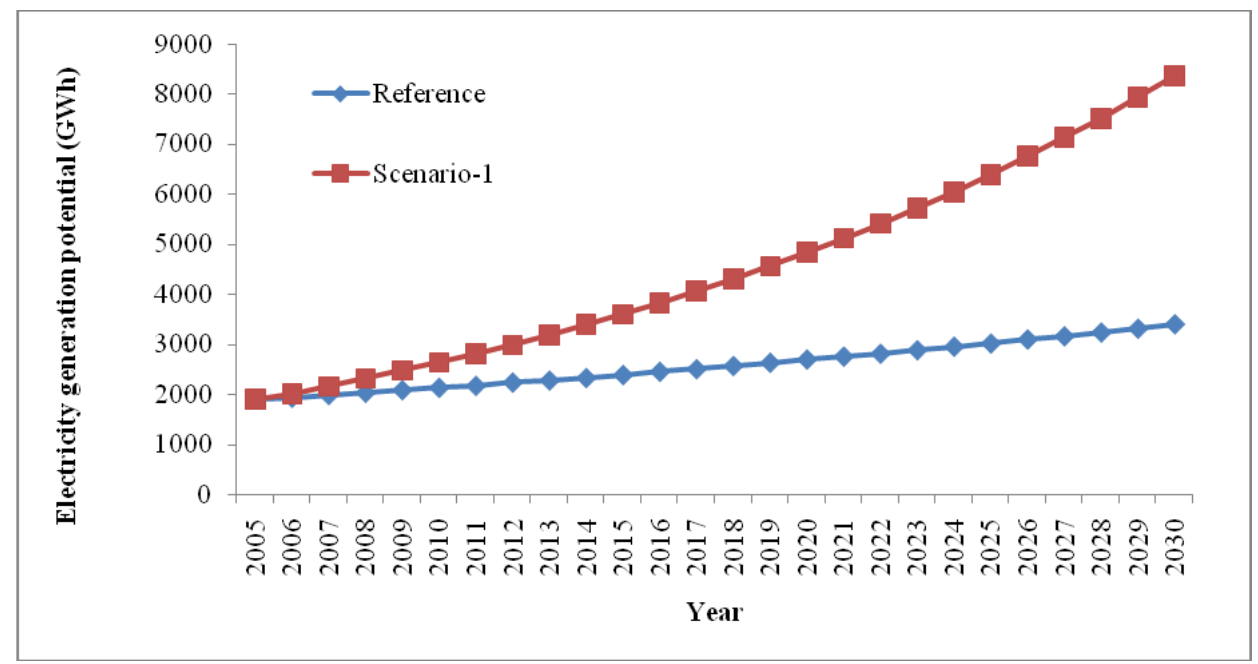

Figure 13. Potential of electricity generation from available rice husk at different scenario for steam turbine technology

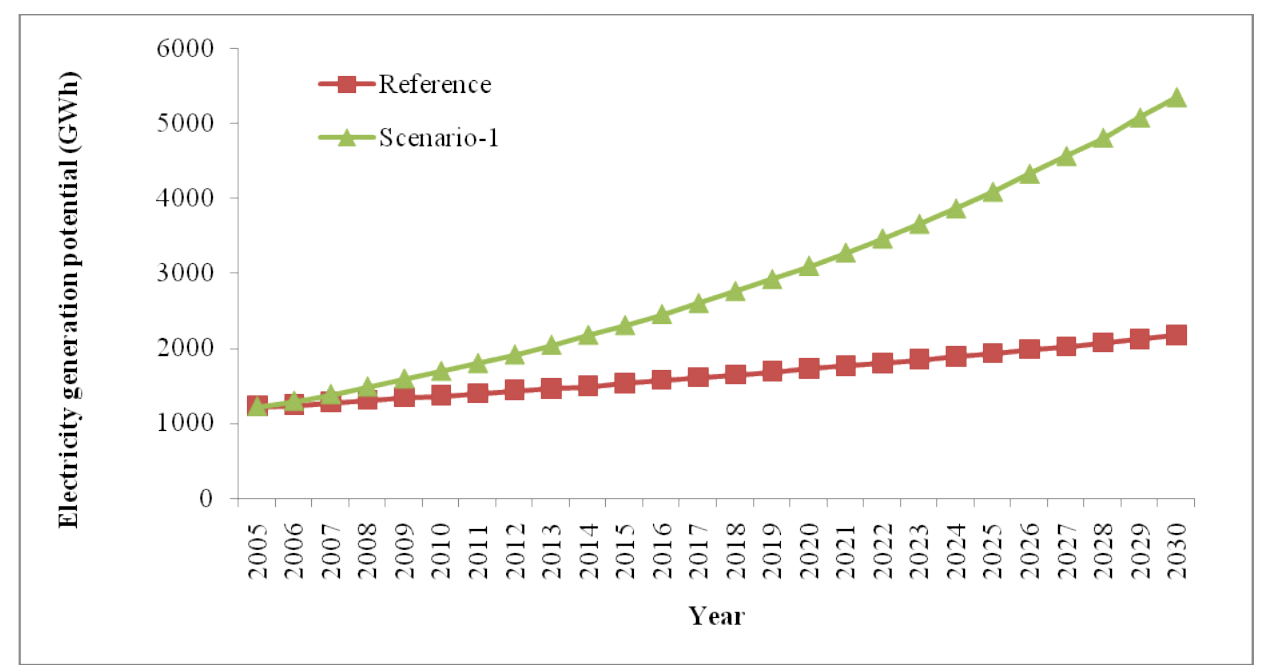

Figure 14. Potential of electricity generation from available husk at different scenarios for gasification based technology 


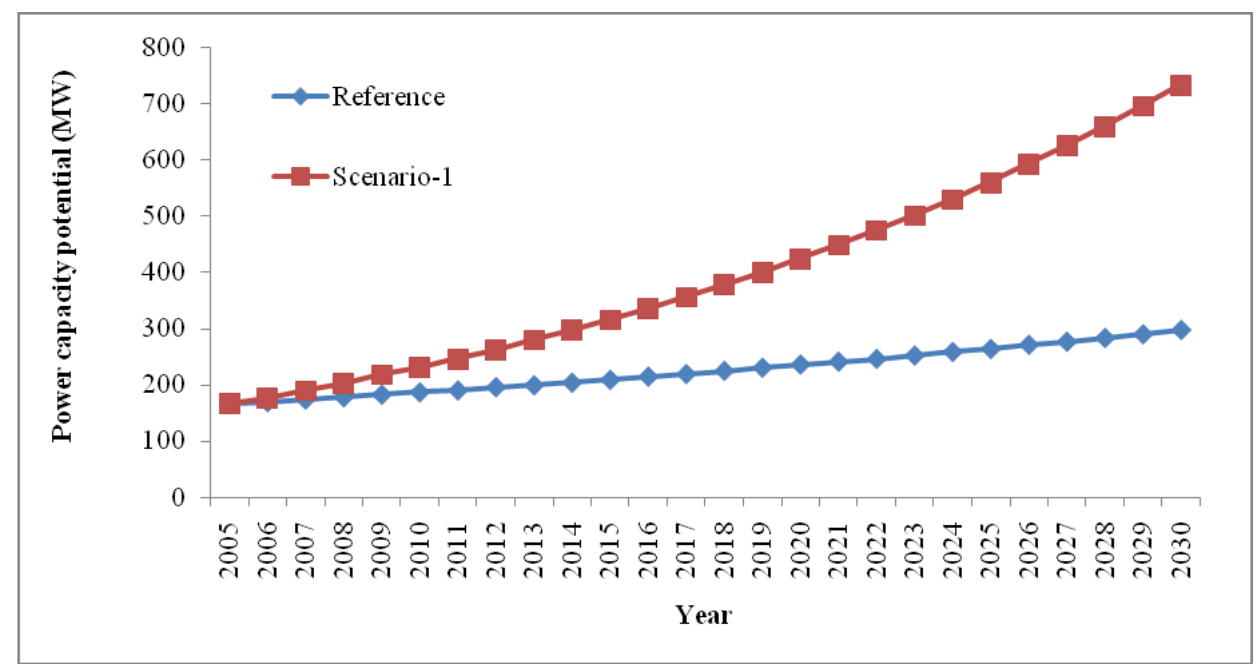

Figure 15. Potential of power capacity from available rice husk at different scenarios for gasification based technology

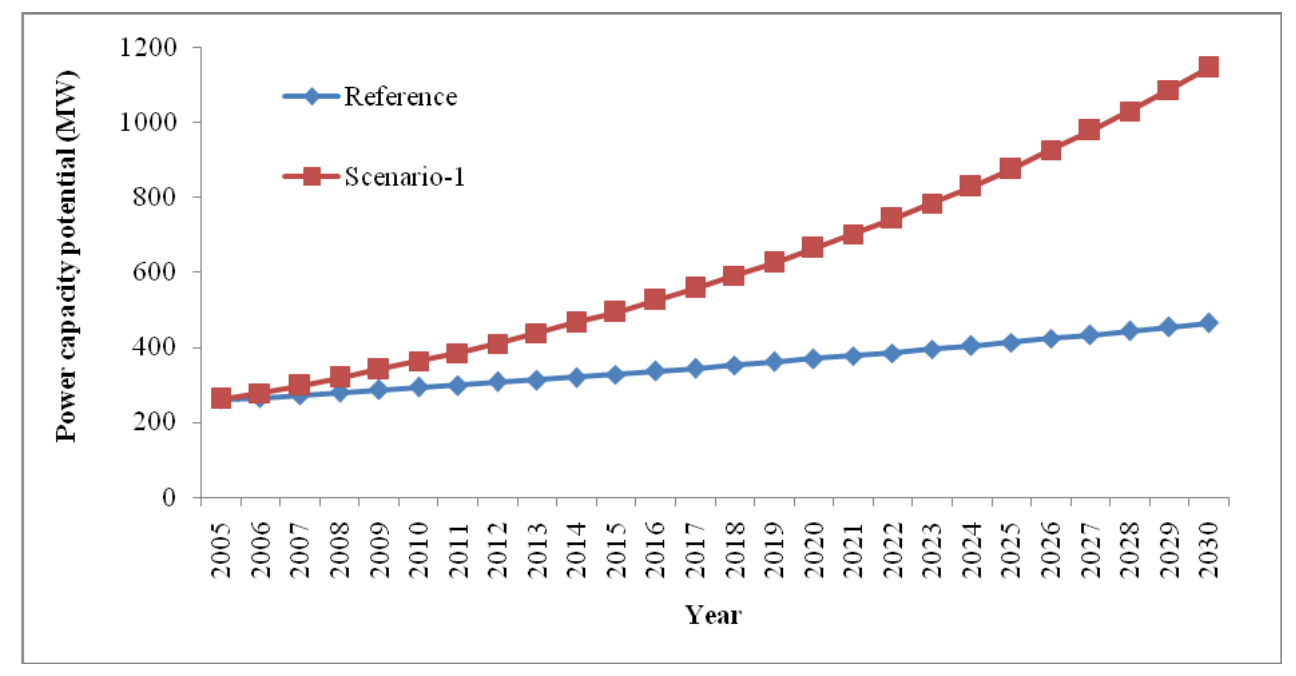

Figure 16. Potential of power capacity from available rice husk at different scenario for steam turbine technology 


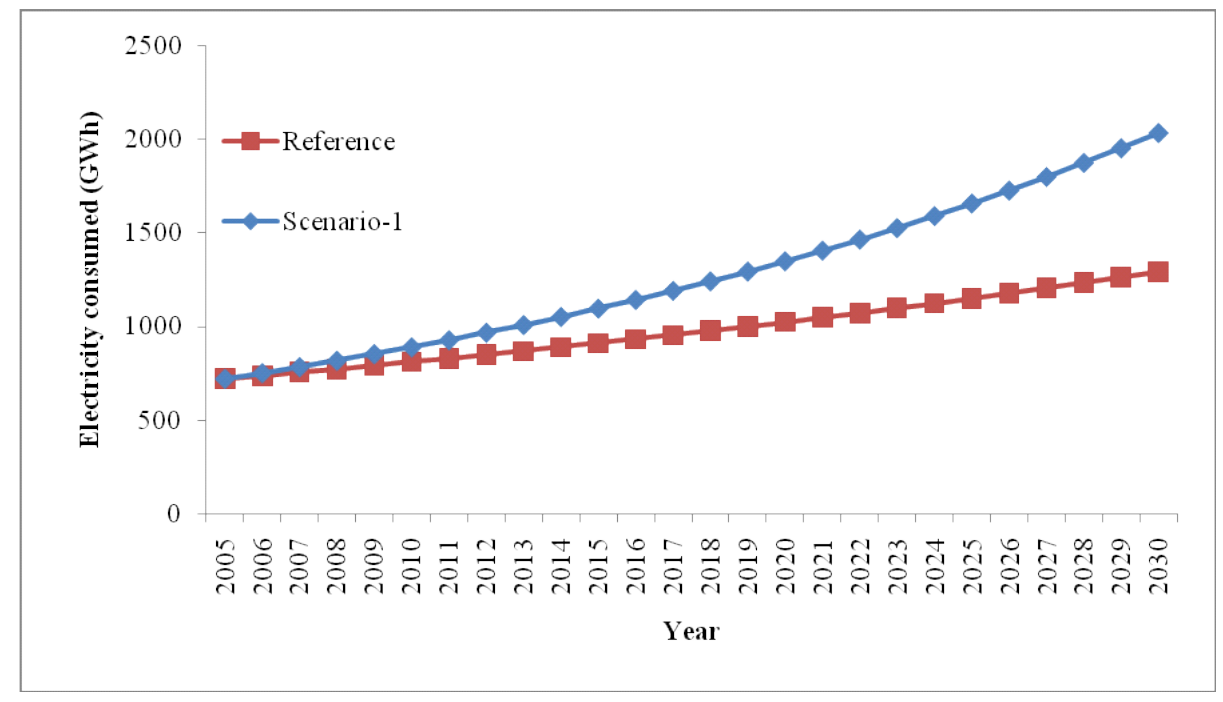

Figure 17. Electricity consumption for rice milling at different scenario

\section{Conclusion}

Power generation from rice husk is modern use of this waste material. The study results conclude that there is a potential to produce electricity from rice husk in selected rice processing zones of Bangladesh. It is estimated that 29 to $41 \mathrm{MW}$ capacity generation plant can be installed in the selected areas based on the available surplus husk after their own consumption. In national context maximum 7682 GWh electricity can be generated from rice husk with a power capacity of $1066 \mathrm{MW}$ in 2030 . The amount of electricity generated from rice husk is sufficient to meet the electricity needed for rice processing purposes. Moreover, surplus amount of electricity could be served to national grid. 


\title{
Apendix
}

\author{
QUESTIONNAIRE FOR THE SURVEY OF RICE MILL \\ WITH SPECIAL FOCUS ON \\ [PRODUCTION, OWN CONSUMPTION AND SURPLUS OF HUSK \& AS WELL AS \\ DATA/INFORMATION ON ELECTRIC POWER CAPACITY]
}

\section{A. GENERAL INFORMATION}

01. Name of the Rice Mill

Tel:

02. Located in (mark $\sqrt{\text { ) }}$ : $\square$ Clusters / $\square$ stand-alone [Location name:

03. District:

\section{B. TECHNICAL INFORMATION}

B1. Paddy processing capacity

04. Types of clean rice produced (mark $\sqrt{ }$ ): $\square$ Parboiled

05. Amount of paddy per batch: (a) Parboiled.............. bag

$\square$ Un-parboiled

(b) Un-parboiled.

$\square$ Puffed rice

(c) Puffed rice.......... bag

...........bag

06. Average number of batch completed in a year:
(a) Parboiled
..batch
(b) Un-parboiled.
..batch
(c) Puffed rice batch

07. Total operating month/days in a year ................. month / days

\section{B2. Parboiling operation of paddy}

08. Time required to complete the parboiling [wm× maúbœ KiłZ KZ mgq] .. hours

09. Husk/bran mix husk consumption: (a) no. of bag/basket

10. Motor capacity for blower feeding of husk:

(a) weight of bag/basket .. $\mathrm{kg}$ .. hp/kW

\section{B3. Drying operation of paddy}

11. Type of drying system (mark $\sqrt{ }$ ): $\square$ Sun drying $\square$ Mechanical $\square$ Hybrid (Sun + Mechanical)

12. Time required for sun drying: ................ days

13. Husk required mechanical drying: (a) no. of bag/basket

(a) weight of bag/basket ...kg

\section{B4. Milling operation of paddy}

14. Type of milling machine (mark $\sqrt{ }$ ): $\square$ Modern rubber roll+polisher $\square$ steel sheller 15. (a) Motor capacity of steel sheller........... kW/hp (b) No. of motor.........................

\section{B5. Amount of husk per batch of paddy processed}

16. Amount of pure husk/bran mix husk

17. Amount of bran

18. Surplus of husk/bran mix husk

19. Purpose of husk buyer:(a) Briquette making (a) No. of bag.

(a) No. of bag.

(b) weight

(b) weight

(b) weight

\section{Other observation (if any).}




\section{Author details}

A.K.M. Sadrul Islam ${ }^{1 *}$ and Md. Ahiduzzaman²

*Address all correspondence to: sadrul@iut-dhaka.edu

1 Department of Mechanical and Chemical Engineering, Islamic University of Technology (IUT), Gazipur, Bangladesh

2 Department of Agro-processing, Bangabandhu Sheikh Mujibur Rahman Agricultural University, Gazipur, Bangladesh

\section{References}

[1] FAOSTAT (2011) http://faostat.fao.org/site/339/default. aspx accessed on 20.8.11

[2] BBS (2009). Statistical yearbook of Bangladesh. Dhaka: Bangladesh Bureau of Statistics, Ministry of Planning.

[3] Ahiduzzaman, M (2007). "Rice Husk Energy Technologies in Bangladesh" Agricultural Engineering International: the CIGR Ejournal. Invited Overview No. 1. Vol. IX. January, 2007.

[4] Ahiduzzaman, M., Baqui, M. A., Tariq, A. S. and Dasgupta, N. (2009). Utilization of Rice Husk Energy for Rice Parboiling Process in Bangladesh. Intl. J. BioRes 6(2):47-79.

[5] Baqui, M. A., Ahiduzzaman, M., Khalequzzaman, M., Rahman, M. M., Ghani, J. and Islam, S.M.F. (2008): Development and Extension of Energy Efficient Rice parboiling Systems in Bangladesh. A Comprehensive Research Report submitted to German Technical Cooperation (GTZ).

[6] Ahiduzzaman, M. and Islam, AKM S (2009). Energy Utilization and Environmental Aspects of Rice Processing Industries in Bangladesh. Energies 2009, 2, 134-149; doi: 10.3390/en20100134.

[7] Singh, R. I. (2007). Combustion of Bio-Mass in an Atmospheric Fbc: An Experience \& Study. Paper presented at the International Conference on Advances in Energy Research Indian Institute of Bombay, December 12-15, 2007

[8] Islam, K. (2008), Senior Adviser, SED project, GIZ, Dhaka. 
